\title{
HEALTH FACILITIES LOCATIONAL ANALYSIS IN MAKURDI LOCAL GOVERNMENT AREA OF BENUE STATE-NIGERIA USING GIS APPLICATION
}

\section{Oboh Satur Okosun}

Department of Geography,

Faculty of Humanities, Management and Social Science, Federal University of Kashere, P.M.B 0182, Gombe State, Nigeria

Email: obohcom@fukashere.edu.ng, obohyian25@yahoo.com

Received:1 October 2018/Revised:7 November 2018/Accepted: 1 December 2018/Published online:31 December 2018

\begin{abstract}
The most important indices of defining general welfare and quality of life of people in the world are the physical and mental health of individuals. The purpose of this study is to examine GIS solution in the spatial analysis of health facilities in Makurdi local government area of Benue State; through mapping of the existing health facilities located in the study area, their spatial distribution pattern, identify areas with marginal services and propose a model for the future development as well examine the availability and accessibility of the existing health facilities, e.g (road network, travel time, distance covered and queuing time). The random sampling method was used in selecting the represented ward and a total 275 questionnaire were distributed, the $\mathrm{x}$ and $\mathrm{y}$ coordinates of the existing Healthcare facilities were collected using the Gemini Global Positioning System (GPS). The" Nearest neighbour analysis" Geospatial statistical method was employed to determine the spatial distribution pattern of the existing health facilities in other to determine the area of limited service and accessibility to healthcare facilities. The results showed that the healthcare facilities are randomly distributed; Fiidi ward was discovered to have limited service as regards the healthcare facilities in the study area. In line with the findings, recommendations were made on the use of GIS to build a concept that can be followed and replicated in divergent social-economic and political contexts. Conclusively, the study had shown that GIS is a vital tool in healthcare facility analysis and also in live application issues and thus should be encouraged in Nigeria for national economic transformation and sustainable development.
\end{abstract}

Keywords: Health, Facilities, GIS, Mapping, Location

\section{Introduction}

Rapid population growth, high level of poverty and lack of available resources within any society has become a problem to adequate and equitable essential health services. Presently, to measure the quality of life individuals, we have to look at the health and health care received by such individual. Health development and management of disease within any society has a 
significant role to play in the development of that society culturally, socially, and economically. The primary goals of any functional public health institutions are to control disease, prevent, disease management, health education and environmental health. Many interrelated changes in the world such as urbanisation, transportation and industrial development, population and life expectation growth, unsustainable agricultural development, cause general and complex environmental problems that threaten the health of humankind.

Dealing with such a complex and multi-aspect problem cannot be in common sense and managing experience of the decision makers in the public health area. Up-to-date information and adequate models are required to help them to decide regarding any of the parameters affecting public health. Thus, one of the significant parameters affecting public health care is its location and accessibility. Location is one of the essential geographic concepts. It has been noted that the location of objects and places is the starting points in all geographic study (Fellman et al., 2005). In addition to its literal meaning, a location is an area, commonly recognised and defined in which activities take place.

According to Atser and Akpan (2009), within developing societies where there are problems with limited facilities and low personal mobility (accessibility), inequality in facilities' distribution is of crucial importance. Accessibility in this context has a spatial theme and signifies the ease with which potential healthcare seekers get to the health facilities unhindered. The proper location/accessibility of public health facilities just like educational service, administrative regions, polling station, is an essential feature of a well developed Nation. Therefore, proper location of facilities should be sort after by planners in the health sector and opinion leaders. Fanan, U.and Felix, K., (2014) was on the opinion that one of the imperatives of health care provision is a concern for both social and spatial justice. Ajala et al (2005) in order to analyse health facilities in Nigeria carried out a research on, accessibility to healthcare facilities as a panacea for sustainable rural development in Osun State, Nigeria using the year 2001 data. From the finding, it was recorded that, severe inequalities exist in the provision of healthcare facilities and services by both the public and private sectors and that the existing distribution pattern is more in favour of urban areas. Also, that the resultant effect of inadequate access to health care delivery on sustainable development can be exemplified by the number of man-hour loss annually to malaria alone which cumulates into lower productivity by workers, this could be traced to effect of distance on patient travel time to health care facilities and as a result the 
estimation of critical distance threshold for different levels of healthcare should be a subject of extensive study.

However, this study lays emphasis on location, accessibility and useful mapping of health facilities and ascertain how GIS can be used to analyse the locational problems (situation) of Health Facilities, which can be achieved by the proper mapping of health facilities (hospitals, dispensary, health centre, maternity, nursing home and private clinics). This GIS technology is not just a magic box as assumed to be by most people, but it is merely an extension of one's analytical thinking because it has no inherent answers, only those of the analyst. It is a tool just as the statistic is a tool; it is thus, handy for proper health care delivery regarding location, accessibility and management.

Accessibility is the measure of the capacity of a location to be reached by, or to reach different locations. Therefore, the capacity and the arrangement of transport infrastructure are key elements in the determination ofaccessibility,for health care facilities the proper location and accessibility just like any other facility is an essential feature of any well developed Nation, but there has been a continuous problem regarding haphazard setup of health facilities without tangible and reliable planning information in Nigeria with Makurdi inclusive. The random location of health facilities in Makurdi has been a significant obstacle in the accessibility of these health centres for prompt services.The location of most public health facilities that render specialised services are influenced by individual connected to high government officials in order to favour their constituency; these facilities are sited in areas where it cannot be accessed easily by the general public.

It is within the scope of this study to find out the existing pattern of location of health facilities and as well map them in the study area. It is assumed that population and distance/accessibility play a crucial role in the location of health facilities (especially the private clinics); thus this study assessed the optimal location of healthcare facilities. It has also been noticed that the type of service rendered and the economic status of the patient/populace informs their choices on the healthcare utilised. Other factors like environment and land suitability are not within the scope of this study.

It is the goal of any development effort by the government to improve the well-being of the generality of the people it governs; making adequate planning for healthcare delivery will be a right step in the right direction. However, adequate planning could only be based on adequate 
information on the existing condition in the planning region. The present study sets out to provide the required information on the existing condition of healthcare facilities in the study area, in other to help in the planning for adequate healthcare delivery system in the study area by looking at; types of healthcare facilities found in the study area, distance/cost travelled, accessibility, estimated number of patients per day and distribution pattern of the healthcare facilities.

\section{Methods}

\subsection{Study Area}

Based on the fact that the research is empirical in nature with specific purpose and focused on a particular location (case study) Makurdi Local Government area which picked. This local Government area is one of the 23 Local Government Area of Benue State; it is situated at the narrow end of the River Benue where the rail bridge is constructed. Makurdi lies on both banks of the river Benue. It is bordered on the west by Keana, north by Lafia and Doma Local Government in Nasarawa State, on the east by Guma Local Government and the south by Gwer and Gwer-West Local Government.

It is located on latitude $7^{\circ} 43^{\prime} 60^{\prime \prime} \mathrm{N}$ and longitude $8^{\circ} 31^{\prime} 60^{\prime \mathrm{E}}$ of the Greenwich meridian. Makurdi Local Government has an area of a 16km radius and is called great Makurdi as provided for in the Greater Makurdi Edict of 1984. It was created in 1970 out of the then Tiv Native Authority. Makurdi local Government later gave birth to Gwer, Guma and the Gwer-West local government areas of the State.

Today Makurdi serves a dual purpose both as a local Government headquarters and also as the state capital. The Local Government has 11 council wards with an estimated population of 500,797 people (2006 population census). It is made up of two constituencies, Makurdi north comprising Agan, Mbalagh, north bank I, north bank II, clerk/market and central south mission. Makurdi south comprises of Ankpa/Wadata, Bar, modern market, Fiidi and wailomayo wards. 


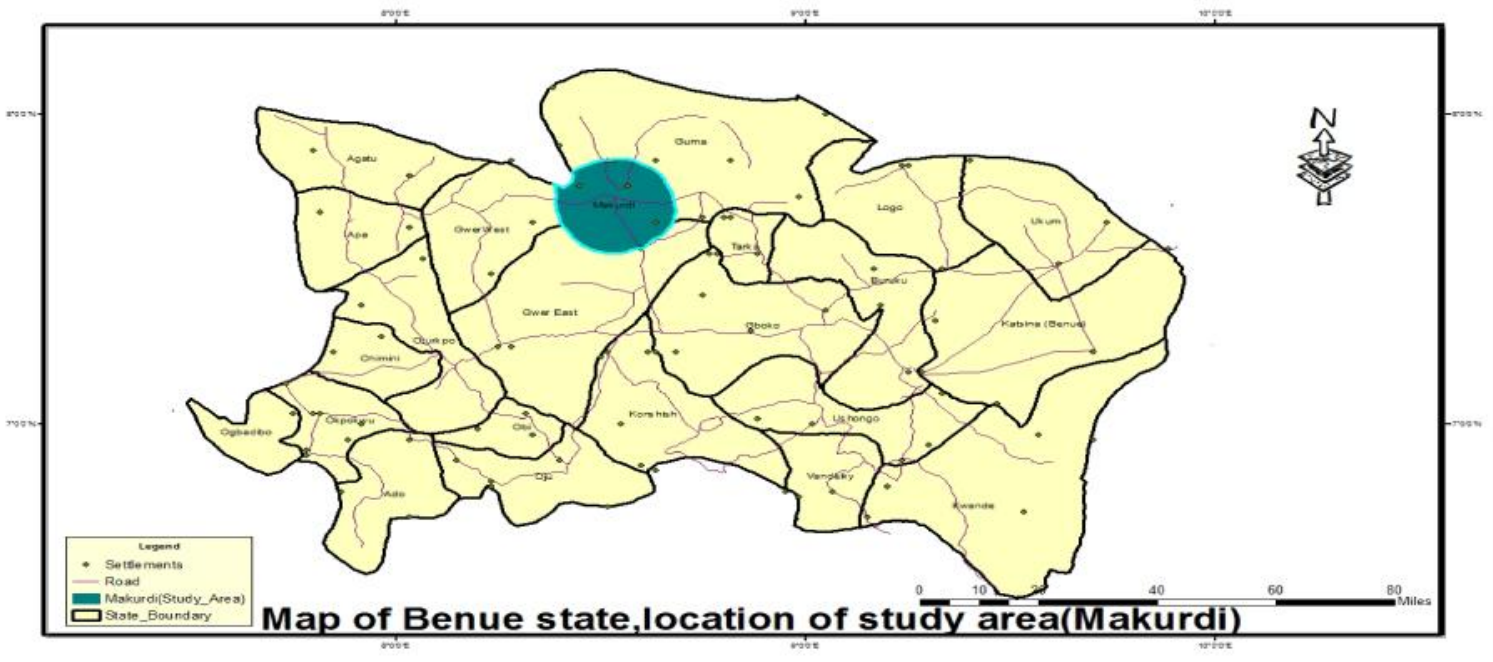

Fig 1. Map of Benue State, Location of Study Area

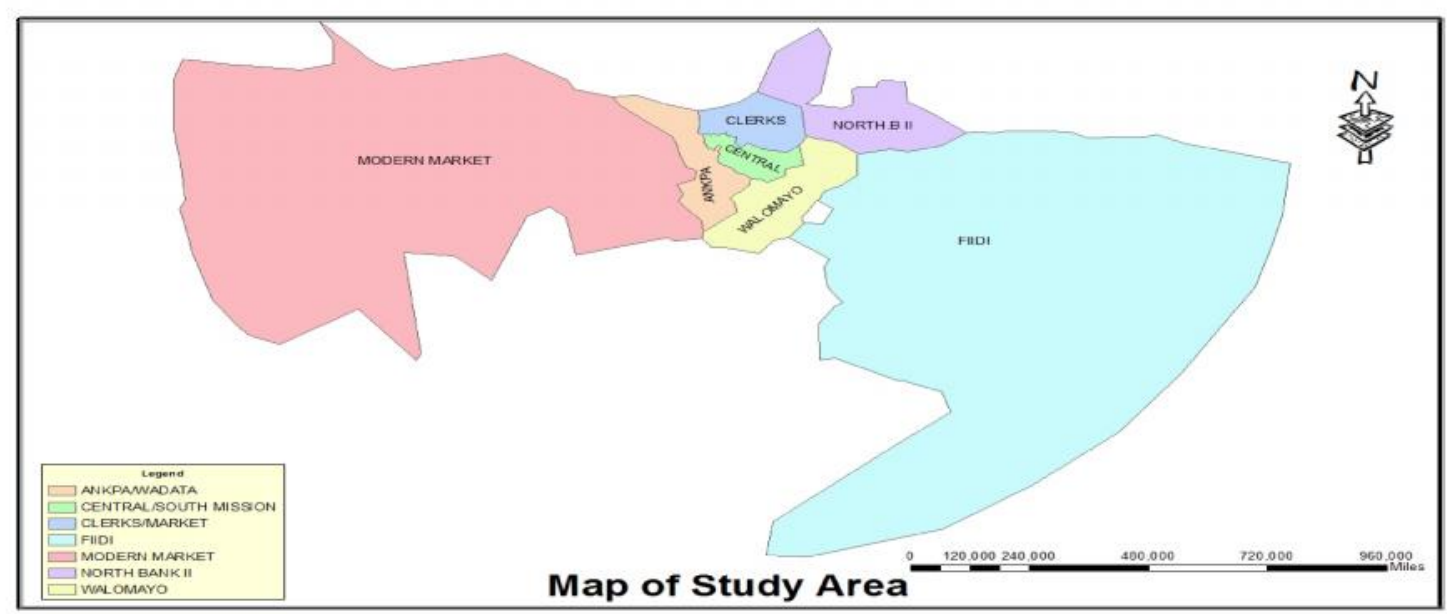

Fig 2. Map of the study ward

\subsection{Sources of data}

The data for this research was sourced from two primary sources;

1. Primary source: This includes the use of Global Positioning System (GPS), to collect data ( $x$ and $y$ ) coordinate on the location of existing Healthcare facilities, distribution of the questionnaire.

2. Secondary Sources (Documented): This includes the use of relevant textbooks, articles, journals, published and unpublished statistics from Ministry of Health, maps from the Ministry of Lands and Survey and Google earth map (raster image). 
The nature of data employed includes, Location of existing Healthcare facilities, Accessibility, travel time, distance covered, travel cost, queuing time (waiting time) and the distance from one hospital to the other.

Makurdi serves as both headquarter of Benue State and also Makurdi Local government. It is made up of eleven (11) wards, and seven (7) wards representing $63.64 \%$ of the total ward were selected using the random sampling method as shown in the table below.

As earlier stated, the random sampling method was used, in which each member in the sampling frame (the population under study) has an equal and independent chance of being included in the sample. The method involves selection at random from a list of the sampling frame (the population) the required number of subjects or element for the sample. Out of the four ways of conducting random sampling, the lottery method popularly called by means of a lottery was used for this work.

Each item (ward) in the sample frame was represented, each ward identified and written on a sheet of paper (1-11) and thoroughly mixed in which a sample of appropriate size ' $n$ ' were picked out randomly without replacement. (see table 1 below).

Table 1: Showing the seven wards selected

\begin{tabular}{cc}
\hline S/N & NAME OF WARDS \\
\hline 1 & Ankpa/ Wadata \\
2 & Fiidi \\
3 & Walomayo \\
4 & Clerk/Market \\
5 & Central South Mission \\
6 & North Bank II \\
7 & Modern Market \\
\hline
\end{tabular}

Sources: Fieldwork 2017

From the Ministry of Health, the list of all registered Healthcare facilities was sourced. From the data, it was possible to identify the location of existing health care facilities within the stipulated ward under survey.

The $\mathrm{x}$ and $\mathrm{y}$ coordinates of the existing Healthcare facilities were collected using the Gemini Global Positioning System (GPS). In totality the study area is made up of (11) as explained earlier, a total of seven (7) wards were randomly selected for the research purpose. From the 7 wards sampled a total number of fifty-five (55) Healthcare facilities were recorded and that includes clinic, Hospitals, Clinic/Maternity, Dispensaries and Health Centre's; as the 
major types of Health facilities. As regards to the questionnaire distribution, a total of two hundred and seventy-five (275) were distributed across the wards, and within each health facility, five (5) patients were sampled as shown in table 2 below. Ankpa/wadata ward has a total of eleven (11) Healthcare facilities, with five (5) patients sampled in each Health Care facility, thus, giving rise to fifty-five (55) questionnaire which accounts for $20 \%$ of the total questionnaire distributed in the study area. Walomayo with a total of 20 healthcare facilities sampled hundred (100) questionnaires which account for $36.36 \%$ of the total questionnaire.

Fiidi has a total of four (4) Healthcare facilities, 20 questionnaires were sampled which accounts for $7.27 \%$. Clerk/market ward has a total of five (2) health care facilities, 10 questionnaires were sampled which accounts for 3.64\%. Central South Mission ward has a total of 7 healthcare facilities, thirty-five (35) questionnaires were sampled which accounts for $12.73 \%$. North Bank II ward has a total of 8 Healthcare facilities, forty (40) questionnaires were sampled which accounts for $14.55 \%$. Lastly, Modern Market ward has a total of five (3) health care facilities, 15 questionnaires were sampled which accounts for $5.45 \%$.

Table 2. Showing questionnaire distribution

\begin{tabular}{lcccc}
\hline \multicolumn{1}{c}{ Wards } & $\begin{array}{c}\text { No of Health } \\
\text { facilities }\end{array}$ & No of Patient & \multicolumn{2}{c}{ Total questionnaire distributed } \\
\cline { 3 - 5 } Ankpa/wadata & 11 & 5 & Number & \% \\
Walomayo & 20 & 5 & 55 & 20 \\
Fiidi & 4 & 5 & 100 & 36.36 \\
Clerk/market & 2 & 5 & 20 & 7.27 \\
Central South & 7 & 5 & 10 & 3.64 \\
mission & & 5 & 35 & 12.73 \\
North bank & 8 & 5 & 40 & 14.55 \\
Modern Market & 3 & 5 & 15 & 5.45 \\
Total & $\mathbf{5 5}$ & & $\mathbf{2 7 5}$ & $\mathbf{1 0 0}$ \\
\hline
\end{tabular}

Sources: Fieldwork 2017

The map showing the location of the various wards was sourced for from the Ministry of Lands and Survey (cartography department) and was scanned into the ArcGIS 10.3 (ArcMap) environment. The map was digitised to show the different layers: wards, boundary, roads, river and significant settlements and ArcGIS 10.3 was also to calculate the spatial distribution pattern 
of the healthcare facilities (Nearest Neighbor analysis). The data were also presented using statistical diagram and statistical mappings such as bar chart, pie chart and histogram, also included is descriptive methods.

\section{Results and Discussion}

\subsection{Types of health facilities}

All the 55 Healthcare facilities within the area under study were grouped into types based on the oral interview conducted between the researcher and doctors. Categorically, the healthcare facilities were grouped into six types across the seven (7) wards which include: clinics/maternity, Hospital, Clinics, Maternity, Dispensary and lastly health centres. This was done based on the function performed by the health facilities. As shown in table 3 below, analyzing the types of health facilities in each ward; Ankpa/Wadata ward has 2(18.18\%) clinic/maternity, hospital 5(45.45\%), Clinic 2(18.18\%), maternity 1(9.09\%), dispensary $1(9.09 \%)$ and health centre none of the entire 11 health facilities in the ward. In Walomayo ward, of all the entire 20 health facilities; clinic/maternity 4(20\%), hospital 8(40\%), clinic 6(30\%), dispensary and health centre has $1(5 \%)$ respectively.

Fiidi ward with 4 health facilities; $1(25 \%)$ for clinic/maternity and $3(75 \%)$ for the hospital. Clerk/market ward with 2 healthcare facilities has 1(50\%) respectively for clinic/maternity and health centre. Central South Mission ward has; 5(71.43\%) for hospital and $2(28.57 \%)$ for the clinic of all the 7 healthcare facilities. North Bank II ward with 8 health care facilities; with 3(37.5\%) clinic/maternity, hospital 3(37.5\%), 1(12.5\%) for maternity and health centre respectively. Lastly Modern market ward has 3 health care facilities; clinic/maternity $1(33.33 \%)$ and clinic 2(66.67\%). In general (entire study area) out of all the 55 healthcare facilities as shown in table 4 below;12(21.82\%) are clinics/maternity with Ankpa/Wadata 2(3.64\%), Walomayo 4(7.27\%), Fiidi, Clerk/market and Modern market has 1(1.82\%) respectively and North Bank II with 3(5.45\%). In totality hospital is 24(43.64\%); Ankpa/Wadata and Central South Mission have 5(9.09\%) respectively, Walomayo 8(14.55\%), Fiidi and North Bank II have 3(5.45\%) respectively.

The Clinic has 12 healthcare facilities; Ankpa/Wadata, Central South Mission and the Modern market have 2(3.64\%) each, Walomayo 6(10.91\%). Maternity has 2 healthcare facilities; with Ankpa/Wadata and North Bank II having 1(1.82\%) each. The Dispensary has 2 healthcare 
facilities; with Ankpa/Wadata and Walomayo having 1(1.82\%) each. Lastly, the health centre is 3; with Walomayo, Clerk/market and North Bank II having 1(1.82\%) each. Fig 3 and 4 below also help to show the location and type of healthcare facilities across the study area

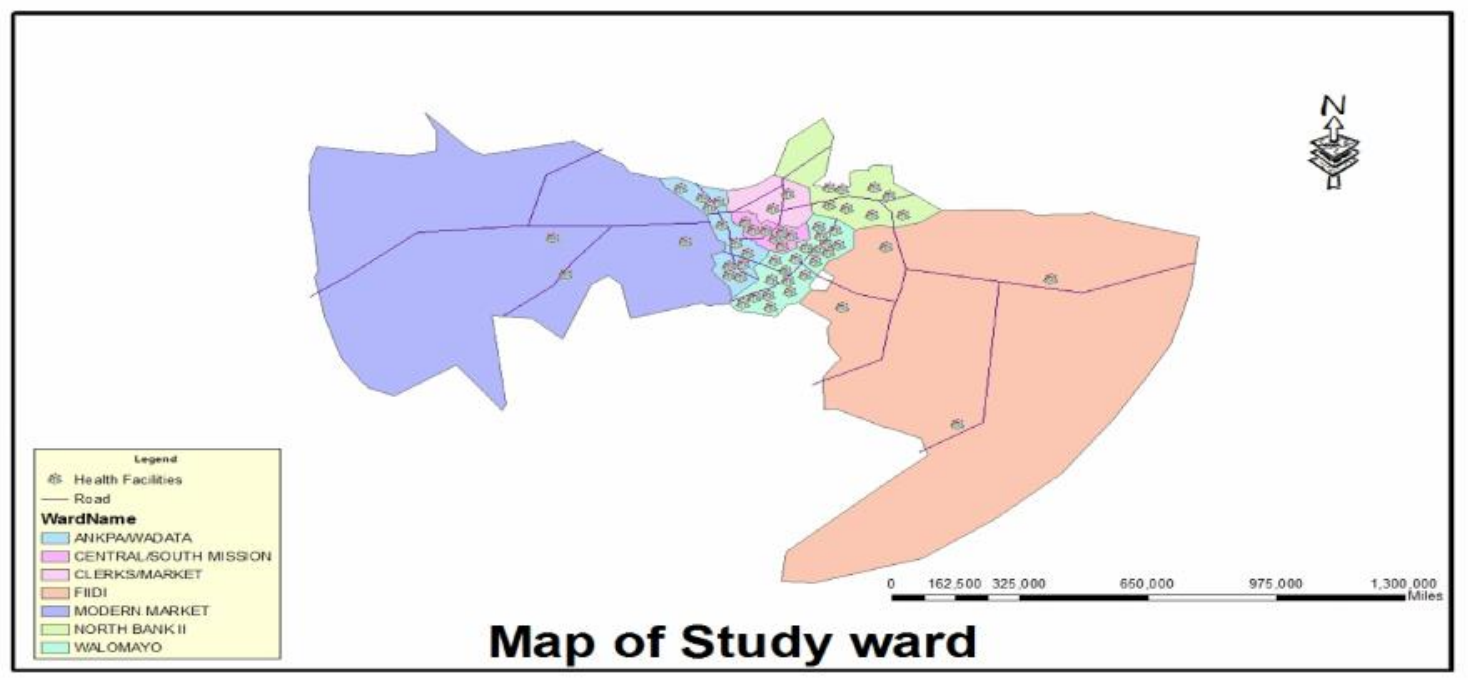

Fig 3. Map of Study Area showing the location of different health facilities.

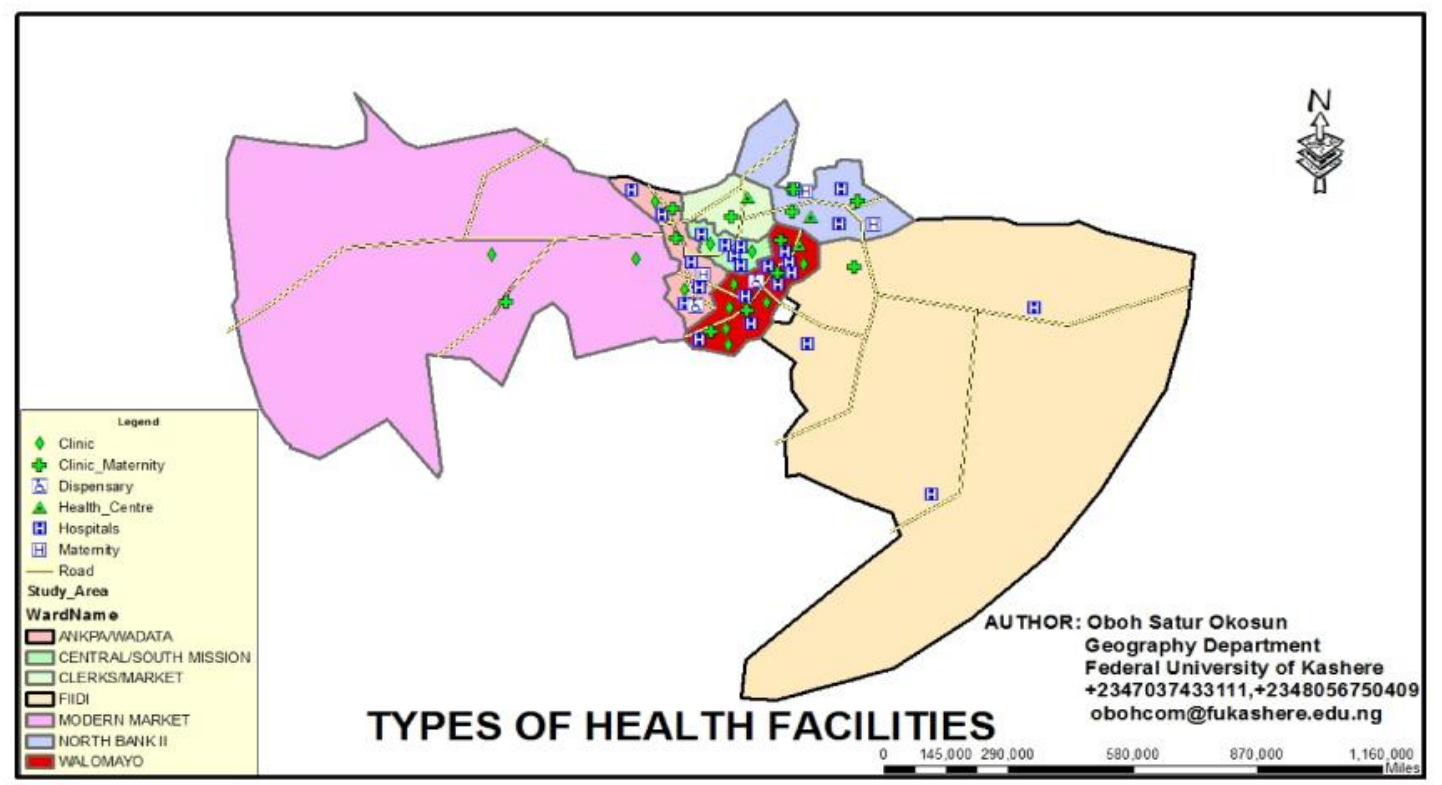

Fig 4: Map of study wards showing the types of health facilities. 
Table 3. Showing types of health facilities within wards.

\begin{tabular}{|c|c|c|c|c|c|c|c|c|c|c|c|c|c|c|c|}
\hline \multirow[t]{2}{*}{$\mathbf{S} / \mathbf{N}$} & \multirow[t]{2}{*}{ WARD } & \multicolumn{2}{|c|}{$\begin{array}{l}\text { CLINIC/MAT } \\
\text { ERNITY }\end{array}$} & \multicolumn{2}{|c|}{ HOSPITAL } & \multicolumn{2}{|c|}{ CLINIC } & \multicolumn{2}{|c|}{$\begin{array}{l}\text { MATER } \\
\text { NITY }\end{array}$} & \multicolumn{2}{|c|}{$\begin{array}{l}\text { DISPEN } \\
\text { SARY }\end{array}$} & \multicolumn{2}{|c|}{$\begin{array}{l}\text { HEALT } \\
\text { H } \\
\text { CENTR }\end{array}$} & \multicolumn{2}{|c|}{ TOTAL } \\
\hline & & NO & $\%$ & NO & $\%$ & NO & $\%$ & NO & $\%$ & NO & $\%$ & NO & $\%$ & NO & $\%$ \\
\hline 1 & $\begin{array}{l}\text { Anakpa/ } \\
\text { Wadata }\end{array}$ & 2 & 18.18 & 5 & 45.45 & 2 & 18.18 & 1 & 9.09 & 1 & 9.09 & - & - & 11 & 100 \\
\hline 2 & $\begin{array}{l}\text { Walomay } \\
\text { o }\end{array}$ & 4 & 20 & 8 & 40 & 6 & 30 & - & - & 1 & 5 & 1 & 5 & 20 & 100 \\
\hline 3 & Fiidi & 1 & 25 & 3 & 75 & - & - & - & - & - & - & - & - & 4 & 100 \\
\hline 4 & $\begin{array}{l}\text { Clerk/Ma } \\
\text { rket }\end{array}$ & 1 & 50 & - & - & - & - & - & - & - & - & 1 & 50 & 2 & 100 \\
\hline 5 & $\begin{array}{l}\text { Central } \\
\text { South } \\
\text { Mission }\end{array}$ & - & - & 5 & 71.43 & 2 & 28.57 & - & - & - & - & - & - & 7 & 100 \\
\hline 6 & $\begin{array}{l}\text { North } \\
\text { Bank II }\end{array}$ & 3 & 37.5 & 3 & 37.5 & - & - & 1 & 12.5 & - & - & 1 & 12.5 & 8 & 100 \\
\hline 7 & $\begin{array}{l}\text { Modern } \\
\text { Market }\end{array}$ & 1 & 33.33 & - & - & 2 & 66.67 & - & - & - & - & - & - & 3 & 100 \\
\hline
\end{tabular}

Sources: Fieldwork 2017

Table 4. Showing types of health facilities in the entire study area.

\begin{tabular}{|c|c|c|c|c|c|c|c|c|c|c|c|c|c|}
\hline \multirow[t]{2}{*}{$\mathbf{S} / \mathbf{N}$} & \multirow[t]{2}{*}{ WARD } & \multicolumn{2}{|c|}{$\begin{array}{l}\text { CLINIC/MATERNIT } \\
\text { Y }\end{array}$} & \multicolumn{2}{|c|}{ HOSPITAL } & \multicolumn{2}{|c|}{ CLINIC } & \multicolumn{2}{|c|}{$\begin{array}{l}\text { MATERNIT } \\
\text { Y }\end{array}$} & \multicolumn{2}{|c|}{ DISPENSARY } & \multicolumn{2}{|c|}{$\begin{array}{l}\text { HEALTH } \\
\text { CENTR }\end{array}$} \\
\hline & & NO & $\%$ & NO & $\%$ & NO & $\%$ & NO & $\%$ & NO & $\%$ & NO & $\%$ \\
\hline 1 & $\begin{array}{l}\text { Anakpa/W } \\
\text { adata }\end{array}$ & 2 & 3.64 & 5 & 9.09 & 2 & 3.64 & 1 & 1.82 & 1 & 1.82 & - & - \\
\hline 2 & Walomayo & 4 & 7.27 & 8 & 14.55 & 6 & 10.91 & - & - & 1 & 1.82 & 1 & 1.82 \\
\hline 3 & Fiidi & 1 & 1.82 & 3 & 5.45 & - & - & - & - & - & - & - & - \\
\hline 4 & $\begin{array}{l}\text { Clerk/Mar } \\
\text { ket }\end{array}$ & 1 & 1.82 & - & - & - & - & - & - & - & - & 1 & 1.82 \\
\hline 5 & $\begin{array}{l}\text { Central } \\
\text { South } \\
\text { Mission }\end{array}$ & - & - & 5 & 9.09 & 2 & 3.64 & - & - & - & - & - & - \\
\hline 6 & $\begin{array}{l}\text { North } \\
\text { Bank II }\end{array}$ & 3 & 5.45 & 3 & 5.45 & - & - & 1 & & - & - & 1 & 1.82 \\
\hline 7 & $\begin{array}{l}\text { Modern } \\
\text { Market }\end{array}$ & 1 & 1.82 & - & - & 2 & 3.64 & - & 1.82 & - & - & - & - \\
\hline & TOTAL & 12 & 21.82 & 24 & 43.64 & 12 & 21.82 & 2 & 3.64 & 2 & 3.64 & 3 & 5.46 \\
\hline
\end{tabular}

Sources: Fieldwork 2017 


\subsection{Total distance covered}

In respect to the distance covered or travelled by the patient to the Healthcare facilities across the various wards were also analysed. The parameter or indices of measurement includes a range of distance $0-1 \mathrm{~km}, 2-3 \mathrm{~km}, 3-4 \mathrm{~km}, 4-5 \mathrm{~km}, 5-7 \mathrm{~km}$ and $8 \mathrm{~km}$ and above. See table 5

Table 5. Showing total distances travelled to health facilities

\begin{tabular}{|c|c|c|c|c|c|c|c|c|c|c|c|}
\hline \multirow[b]{2}{*}{ WARD } & \multicolumn{10}{|c|}{ DISTANCE COVERED IN KILOMETERS (KM) } & \multirow[b]{2}{*}{ Total } \\
\hline & 0-1 & $\%$ & $2-3$ & $\%$ & 4-5 & $\%$ & 6-7 & $\%$ & $\begin{array}{l}8 \text { \& } \\
\text { above }\end{array}$ & $\%$ & \\
\hline $\begin{array}{l}\text { Ankpa- } \\
\text { wadata }\end{array}$ & 10 & 18.18 & 15 & 27.27 & 15 & 27.27 & 10 & 18.18 & 5 & 9.09 & 55 \\
\hline Walomayo & 40 & 40 & 30 & 30 & 20 & 20 & 7 & 7 & 3 & 3 & 100 \\
\hline Fiidi & 5 & 25 & 10 & 50 & 3 & 15 & 2 & 10 & - & - & 20 \\
\hline Clerk/market & 10 & 40 & 7 & 28 & 5 & 20 & 2 & 8 & 1 & 4 & 25 \\
\hline $\begin{array}{l}\text { Central } \\
\text { South } \\
\text { Mission }\end{array}$ & 10 & 28.57 & 12 & 34.28 & 7 & 20 & 4 & 11.42 & 2 & 5.71 & 35 \\
\hline $\begin{array}{l}\text { North Bank } \\
\text { II }\end{array}$ & 8 & 20 & 12 & 30 & 10 & 25 & 5 & 12.5 & 5 & 12.5 & 40 \\
\hline
\end{tabular}

Source: Fieldwork 2017

\subsection{Cost of distance travelled}

The cost of distance travelled is the fare paid to health facilities of a patient's choice which could be a hospital, clinic, and maternity. Table 6 below help to explain better.

Table 6. Showing cost of travel to health centres

\begin{tabular}{llllllll}
\hline Wards & $\mathbf{5 0 - N 1 0 0}$ & $\mathbf{\%}$ & $\mathbf{1 0 0}-\mathbf{N 3 0 0}$ & $\mathbf{\%}$ & $\mathbf{N 5 0 0}$ above & \% & Total \\
\hline $\begin{array}{l}\text { Ankpa- } \\
\text { wadata }\end{array}$ & 30 & 54.54 & 10 & 18.18 & 15 & 27.27 & 55 \\
$\begin{array}{l}\text { Walomayo } \\
\text { Fiidi }\end{array}$ & 60 & 60 & 25 & 25 & 15 & 15 & 100 \\
Clerk & 10 & 40 & 7 & 35 & 5 & 25 & 20 \\
market & & 40 & 8 & 32 & 7 & 28 & 25 \\
$\begin{array}{l}\text { Central } \\
\text { S.Mission }\end{array}$ & 20 & 51.14 & 10 & 28.57 & 5 & 14.28 & 35
\end{tabular}




\begin{tabular}{llllllll}
\hline North bank & 15 & 37.5 & 15 & 37.5 & 10 & 25 & 40 \\
II & & & 75 & & 57 & & \\
Total & 143 & & 75 &
\end{tabular}

Sources: Fieldwork 2017

\subsection{Accessibility}

Concerning how accessible the health facilities are, 3 significant responses of the survey stipulated that the road are bad, 22 responded to fair, 195 responded to good roads and the remaining 55 responded to perfect roads. Table 7 below is the tabular representation of the survey result.

Table 7. Showing accessibility to healthcare facilities

\begin{tabular}{llllllllll}
\hline Ward & Bad & $\%$ & Fair & $\%$ & Good & $\%$ & $\begin{array}{l}\text { Very } \\
\text { good }\end{array}$ & \% & Total \\
\hline Ankpa-wadata & 3 & 5.45 & 10 & 18.18 & 40 & 72.72 & 2 & 3.63 & 95 \\
Walomayo & - & - & 5 & 5 & 85 & 85 & 10 & 10 & 100 \\
Fiidi & - & - & - & - & 20 & 100 & - & - & 20 \\
Modern Market & - & - & - & - & 10 & 40 & 15 & 60 & 35 \\
Central S. M & - & - & 5 & 5 & 15 & 42.85 & 15 & 42.85 & 35 \\
North Bank II & - & - & 2 & 10.5 & 25 & 62.5 & 13 & 32.5 & 40 \\
\hline & 3 & 5.45 & 22 & 28.68 & 195 & & 55 & & 275 \\
\hline
\end{tabular}

\section{Source: Fieldwork 2017}

\subsection{Estimated number of patients per day}

In regards to the patient influx per day, the following results as shown in table 8 below were obtained from all the sampled hospitals.

Table 8. Estimate of patient per day

\begin{tabular}{lllll}
\hline S/N & WARD & Name of Health Facilities & $\begin{array}{l}\text { Type of Health } \\
\text { facility }\end{array}$ & $\begin{array}{l}\text { Patients } \\
\text { per day }\end{array}$ \\
\hline $\mathbf{1}$ & Ankpa wadata & Bethel clinic \& maternity & Clinic \& maternity & 10 \\
& & Hope clinic \& maternity & Clinic \& maternity & 10 \\
& & Nations hospital & Hospital & 22 \\
& & Federal medical centre & Hospital & 60 \\
& & Mercyland hospital & Hospital & 15 \\
& & Riverside federal hospital & Hospital & 20 \\
& & Musab hospital & Hospital & 20 \\
& & Julua clinic \& maternity & Maternity & 11 \\
& & Adikwu memorial & Dispensary & 15 \\
& & Alheri clinic & Clinic & 07 \\
$\mathbf{2}$ & \multirow{4}{*}{ Walomayo } & Primary health care & Clinic & 20 \\
& & Abama clinic \& maternity & Clinic \& maternity & 10 \\
& & Epidemiology unit & Health centre & 20
\end{tabular}


Benue Brewery clinic

Yima hospital

Immaculate conception

Empathy clinic

Wurukm specialist hospital

Kings paaks clinic

Kings cross clinic \& maternity

Blue cross specialist

Tosema specialist

Fabash herbal clinic

Queens clinic \& maternity

S.A herbal centre

Bright way dispensary

Bishop murray medical

Benue hospital

Pampas hospital

Hemko hospital

$3 \quad$ Fiidi

4 Clerk/Market

5 Central South Mission

$6 \quad$ North Bank II

$7 \quad$ Modern Market
El- shaddai hospital

Federal medical centre

Airforce base hospital

Fiidili clinic \& maternity

Unity hospital \& maternity

Benue women clinic

Winners hospital

Samara hospital

Family support program

Psychiatric unit

Judita hospital

City hospital

Dora clinic

Harmony clinic \& maternity

Primary healthcare centre

Dora specialist hospital

Samaritan specialist hospital

Savior medical hospital

St. sabastine clinic

Linester clinic \& maternity

Genein hospital

Immanuel medical specialist

Vakion clinic \& maternity

Pishon women clinic
Clinic $\quad 10$

Hospital 15

Hospital 20

Clinic $\quad 10$

Clinic $\quad 10$

Clinic \& maternity 12

Clinic \& maternity 12

Hospital 09

Hospital $\quad 30$

Clinic 05

Clinic \& maternity 15

Clinic $\quad 10$

Dispensary $\quad 15$

Hospital 25

Hospital 20

Hospital 15

Hospital 22

Hospital 20

Hospital 55

Hospital 12

Clinic \& maternity 11

Health center $\quad 15$

Clinic \& maternity 13

Hospital 15

Hospital 20

Clinic 15

Hospital 10

hospital 15

hospital 15

Clinic 13

Clinic \& maternity 20

Health centre $\quad 15$

Maternity 20

Hospital 15

Hospital 20

Clinic \& maternity 13

Clinic \& maternity 15

Hospital 20

Clinic $\quad 10$

Clinic \& maternity 15

Clinic $\quad 18$ 


\subsection{Distribution Pattern}

One of the objectives of this work was to determine the spatial distribution pattern of the hospital. From the analysis carried out, using the ArcGIS 10.3 software, it was discovered that the health facilities in the study are not regularly distributed but randomly distributed at a significant level of 0.05 and a critical level of 1.96, as shown in fig 5 below. The distance covered in table 5 and 6 above also gave a picture of the distribution pattern of the health care facilities.

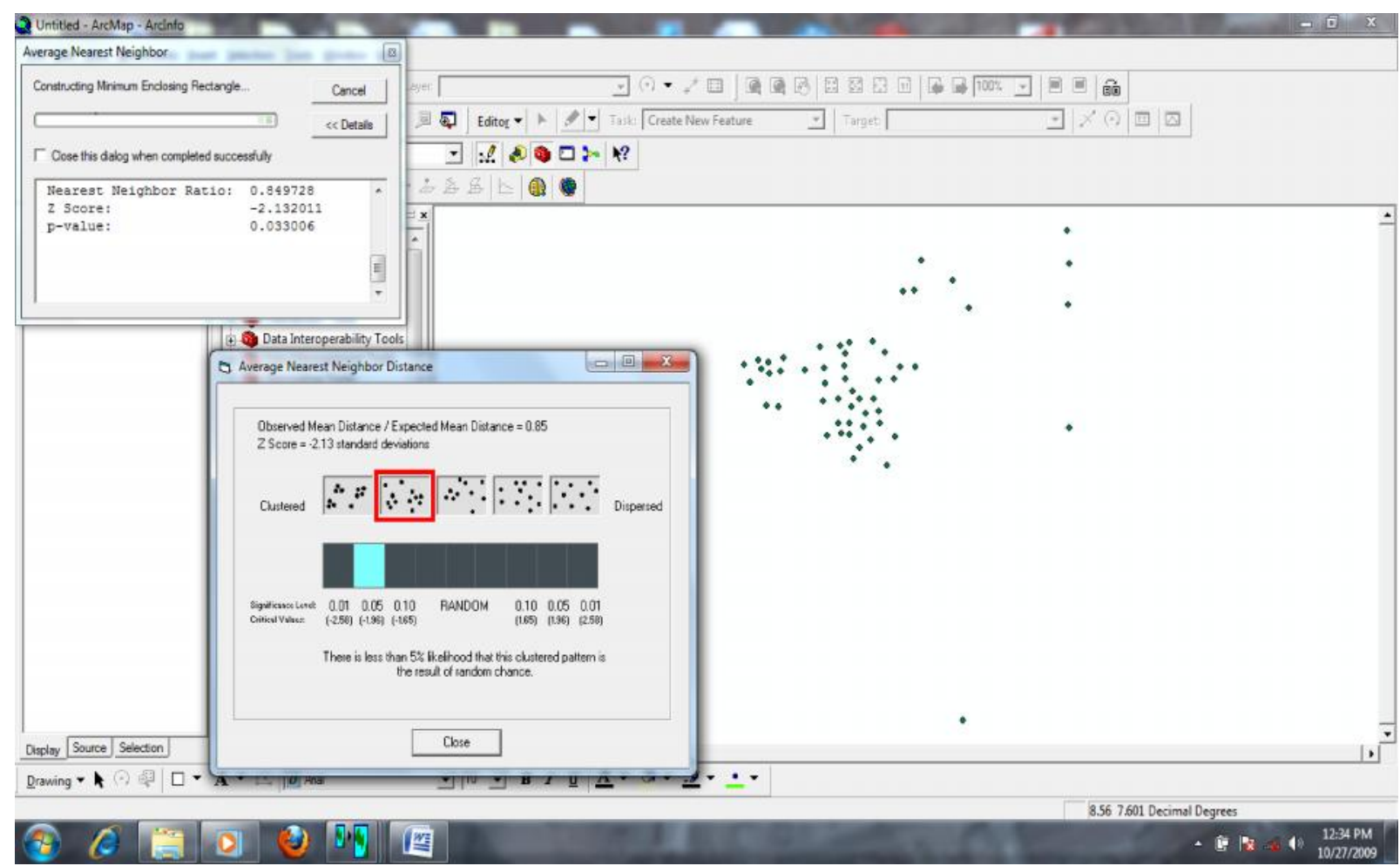

Fig 5: Map of the analysis showing nearest neighbour analysis

\subsection{Summary of the finding}

The study of GIS usefulness in spatial analysis of health facilities is an avenue to put up appropriate strategies for approving Health care services in the national level, State and Local government level (grassroots).

The main aim and relevant objectives in which this study is targeted at have been duely achieved. It is thus imperative to mention that the study has been able to make the following remarks (observations). 
- Before this time there exist, no map chart or graph showing the location of healthcare facilities in the study except for the list and address of all the registered Health care facilities.

- It was discovered that most of the location of Health facilities in the Health manual sourced from the ministry of health is not in existence.

- From the findings, it was discovered that all the fifty-five (55) health facilities surveyed are about six (6) types or categories which includes;

- Hospitals

- Clinics and Maternity

- Clinics

- Dispensary

- Health centres

- Maternity

- Some of the few specialist hospital and services rendered are as follows,

Federal Psychiatric unit renders Psychiatric services, the Epidemiology unit renders epidemiological services (Epidemic breakout), and Tuberculosis unit renders treatment for T.B patients and Blue Cross hospital which offer orthopaedic services for a broken bone.

- Concerning the distribution pattern of the existing Health facilities, it was discovered that the Health facilities are randomly distributed.

- From the fair pools given regarding accessibility, it was discovered that most of the roads to Health facilities are excellent and accessible.

\subsection{Recommendation}

The recommendation given here is to enhance future studies on Health care facilities, GIS for spatial analysis of Health facilities in Nigeria, Africa and the world in general. The GIS coordinates will be useful for positioning Health care services and facilities. This will provide the basis for health facility audit and creation of master facilities in the State.

The map produced can provide bases for referral in the following ways;

- Distribution of health facilities

- Distribution of numbers of Doctors

- A suitable location for future Health facilities. 
The map produced should not be seen as the final product but as a yardstick or a bearing for mapping health facilities as it is obtainable in the developed world. GIS has been not a magic box; it is also not an end to everything but a means to it. The Map produced at this level should be seen as a way forward.

The newly created database on the location of health facilities should be regularly reviewed and updated for maximum benefit. The nature of the distribution of health facilities should be given all the urgent attention needed. Places that lack adequate Health facilities services like clinics, Hospitals, Health centre's etc. should be provided for each ward and appropriately distributed within the wards.

Specialised Hospitals like Blue Cross who offers strictly orthopaedic services and also Psychiatric Hospital should be provided within all the wards to enable the citizens of the Local government to have easy access to such services. Lastly, the Staff of the Local government, State government and Ministry of Health should be trained on how to create Health service maps based on the following, Cartography, web-based GIS application, use of GPS and access to Google earth.

\section{Conclusion}

In spite of the high level of constraints that may be involved in the implementation of some of the listed recommendations, notwithstanding, the researcher calls for the cooperation of the government at all level, (NGO) Non-Governmental Organization, the Ministry of health and its Agencies, the relevant authorities and the general public at large to support the drive.

With no part removed or left out, it is the candid opinion of the researcher that if all stake holder adopt the recommendation stipulated by the researcher, a meaningful improvement will be undoubtedly attained. This will, in turn, bring about an improved health care system in Nigeria which will be free and accessible to all.

The researcher, therefore suggests that further areas on this topic should avail to cover studies of GIS and health facilities mapping, GIS and health service, GIS and public health. Studies can be carried out in other departments like Universities, NGO, private and public institution or countries as this will help in making the empirical comparison within the department, NGO, Public/Private institution, countries and universities in regards to their constraints. 
Conclusively, it is suggested that use of GIS for health facilities and live application issues, should be encouraged as it is relatively a new technique or tool for this significant part of the world.

\section{Acknowledgement}

For His enabling grace, divine wisdom and vision for writing this work, the Almighty GOD takes prime position in our expression of appreciation and gratitude. My unreserved appreciation goes to my wife (Okosun Obekpa Mercy) and my two lovely daughters (Okosun Hadassah Oyale Onose and Okosun Ariel Abahi Ainose). Lastly for those who believe in the beauty of Geography, Cartography and GIS

\section{References}

Ajala, O.A., Sanni, L., and Adeyinka, S.A., (2005). Accessibility to Healthcare Facilities: A Panacea for Sustainable Rural Development in Osun State, South western Nigeria. Journal of Human Ecology, 18(2):121 - 128.

Amer, S., (2007). Toward Spatial Justice in Urban Health Services Planning. PhD.Dissertation, ITC, Enschede, The Netherlands.

Atser J., and Akpan, P.A., (2009). Spatial Distribution and Accessibility of Health Facilities in Akwa Ibom State, Nigeria. Ethiopian Journal of Environmental Studies and Management (EJESM) Vol.2 (2): pp. 49-57.

Fagbeja, M.A., (2000). Mapping the Incidences of Chronic Bronchitis and Bronchopneumonia and Verification of High-Risk Areas Using GIS. M.Sc.Dissertation, University of Ibadan, Ibadan, Nigeria.

Fanan, U., and Felix, K. (2014). Analysis of the Spatial Distribution of Health Facilities in Benue State, Nigeria ,Public Health Research 2014, 4(5): 210-218.DOI: 10.5923/j.phr.20140405.09

Ogundare, E.I., (1982). Healthcare Delivery is a success in Oyo State. p.7 October 27, Daily Sketch, Lagos-Nigeria. 